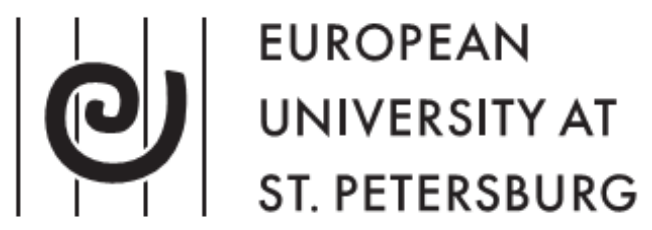

Kirill Borissov

Ram Sewak Dubey

A Characterization of

Ramsey Equilibrium

in a Model with Limited Borrowing

Working paper Ec-08/13

Department of Economics

St. Petersburg

2013 


\section{УДК 330.35}

\section{ББК 65.012.2}

B78

Европейский университет в Санкт-Петербурге

Кирилл Борисов, Рам Севак Дюбей

Характеризация рамсеевского равновесия в модели с

ограниченными заимствованиями

На английском языке

Borissov K., Dubey R. S. - A Characterization of Ramsey Equilibrium in a Model with Limited Borrowing - European University at St. Petersburg, Department of Economics. Working Paper Ec-08/13, 20 p.

Abstract: We investigate the convergence property of the capital stock sequence in Ramsey equilibria with limited borrowing by the households. In our model, at the beginning of each period, households are allowed to borrow against their end of the period wage income. Under this assumption the capital stock sequence converges to the steady state stock irrespective of the technology and turnpike property holds in every Ramsey equilibrium.

Keywords: Ramsey Equilibrium, Limited Borrowing, Convergence of capital path

JEL Classification: C61, D61, D90, O41

\section{Kirill Borissov}

European University at St. Petersburg, 3 Gagarinskaya Street,

St. Petersburg, 191187, Russia, e-mail: kirill@eu.spb.ru

\section{Ram Sewak Dubey}

Department of Economics and Finance, Montclair State

University, Montclair, NJ 07043;

e-mail: dubeyr@mail.montclair.edu.

(C) K. Borissov, R. S. Dubey, 2013 


\title{
A Characterization of Ramsey Equilibrium in a Model with Limited Borrowing
}

\author{
Kirill Borissov, $\quad$ Ram Sewak Dubey ${ }^{\dagger}$
}

October 2, 2013

\begin{abstract}
We investigate the convergence property of the capital stock sequence in Ramsey equilibria with limited borrowing by households. In our model, at the beginning of each period, households are allowed to borrow against their end of the period wage income. Under this assumption the capital stock sequence converges to the steady state stock irrespective of technology and turnpike property holds in every Ramsey equilibrium.

Keywords: Ramsey Equilibrium, Limited Borrowing, Convergence of capital path.

Journal of Economic Literature Classification Numbers: C61, D61, D90, 041 .
\end{abstract}

${ }^{*}$ Corresponding Author, European University in St. Petersburg, 3 Gagarinskaya Street, St. Petersburg, 191187 RUSSIA, and St. Petersburg Institute for Economics and Mathematics (Russian Academy of Sciences), 1 Tchaikovsky Street, St. Petersburg, 191187 RUSSIA; E-mail: kirill@eu.spb.ru

${ }^{\dagger}$ Department of Economics and Finance, Montclair State University, Montclair, NJ 07043; E-mail: dubeyr@mail.montclair.edu. 


\section{Introduction}

The "folklore result" on Ramsey equilibria is that eventually the most patient household owns the entire capital stock of the economy. The comprehensive survey paper by Becker (2006) points out that this result holds not in general, but only if the capital stock sequence converges to the steady state stock. The latter in turn is guaranteed only under some special assumption about technology.

In this paper, we revisit the issue of convergence of the capital stock sequence and the ownership pattern of capital in a standard dynamic model of Ramsey equilibrium by relaxing the borrowing constraint to allow households to borrow at the beginning of any period against the wage income paid at the end of the period.

In the literature on Ramsey equilibria, one says that a turnpike property obtains if every household other than the most patient one eventually reaches a no capital position and maintains that state thereafter. An example by Michael L. Stern, reported in Becker (2006), shows that without additional assumptions about technology and/or preferences, this turnpike property does not obtain. The general result on long-run behavior of Ramsey equilibria that has been established by Becker and Foias (1987) is the following recurrence theorem: the no capital state is recurrent for every household other than the most patient one. That is, for every household other than the most patient one, it is the case that no capital is owned infinitely often.

A result reported in Becker and Mitra (2012), can be used to infer that if a Ramsey equilibrium satisfies the turnpike property, then it satisfies the transversality condition of Malinvaud (1953) and is therefore intertemporally efficient, in terms of the aggregate consumption stream that it provides. This result provides a link between the ownership pattern of capital and the efficiency of Ramsey equilibria. In particular, the result implies that when the turnpike property on the ownership of capital is satisfied, the Ramsey equilibria must be efficient, even though the notion of a Ramsey equilibrium involves borrowing constraints, a possible source of inefficiency.

The turnpike property, which is asymptotic in nature, places restric- 
tions on the Ramsey equilibrium path itself, and is in general hard to check, given the primitives of the model (i.e., specification of production and utility functions, and discount factors of agents). To overcome this problem, the approach taken in the literature has been to note that if the capital stock sequence along a Ramsey equilibrium path converges, then the turnpike property on the ownership pattern of capital holds (a result due to Becker and Foias (1987)). One can then seek restrictions on the primitives of the model under which such a convergence property holds.

The basic result, following this approach, is that if capital income is monotonically increasing in capital stock, then the capital stock sequence along a Ramsey equilibrium path must converge (Becker and Foias (1987)). In Becker et al. (2013), this condition has been generalized to the monotonicity of the maximal income that a single agent can have. This is the capital income when the agent holds the entire capital stock plus the agent's wage income. It has been shown that if this maximal income is monotonically increasing in capital stock, then the capital stock sequence along a Ramsey Equilibrium path must converge.

Mitra and Sorger (2013) instead of looking at plausible restrictions on the production technology leading to the monotonic properties noted above, investigate a continuous time version the Ramsey economy as was proposed originally by Ramsey (1928). In the continuous time model, they show that the most patient household owns the entire capital of the economy after some finite time in every Ramsey Equilibrium. Further, they demonstrate that every Ramsey Equilibrium in their model is intertemporally efficient. The results of their paper differ strikingly from the literature on discrete-time versions of the Ramsey economy, and the difference appears to arise entirely from the difference in the modeling of time ${ }^{1}$.

The standard Ramsey model takes an extreme view on the borrowing by households and disallows it altogether, i. e. the market is incomplete in an extreme sense. In contrast, in a general economic growth model with

\footnotetext{
${ }^{1}$ However, it is worthwhile to note that Borissov (2011) considers a discrete-time Ramsey economy where the wage paid to workers on an ex-ante basis instead of the usual assumption of wage being paid on an ex-post basis. With this change, he establishes the convergence of the capital input sequence without putting any additional structure on the production function (like capital income monotonicity or maximal income monotonicity).
} 
a representative household the borrowing is completely unrestricted, i. e. the market is complete. The same assumption is made in early models with heterogeneous consumers (see e.g. Bewley (1982)). Bewley (1982) shows that in an economy with a complete market (i.e. where households can borrow against the value of the initial capital owned and the present value of their life time wage income), the consumption for all households other than the most patient one is zero after some finite time in every equilibrium. This result also established a link between the dynamic general equilibrium theory and turnpike theory. Becker (2006) has observed that these dynamic equilibria lead to an outcome that even though the impatient households have zero consumption after a finite time, they continue to provide labor services for ever, which does not appear to be very realistic.

Many real life situations lie in between these two extremes, in the sense that the markets are not complete as in Bewley (1982), but not incomplete as in Ramsey economies with no borrowing. We make a one-step deviation from the discrete-time standard Ramsey model and allow one period borrowing by households. More specifically, at the beginning of each period the households are allowed to borrow against their end of the period wage income. Our objective is to explore the nature of the capital sequence observed in equilibrium and seek the convergence property of the capital stock sequence. We are able to demonstrate that this relatively mild relaxation of the debt constraint leads to convergence of the aggregate capital stock sequence without any additional assumptions about production technology. Not only this establishes the turnpike property of the equilibrium path but also it shows that the equilibrium outcome is efficient.

The rest of the paper is organized as follows. In section 2, we introduce the production technology and households' characteristics. Section 3 describes a discrete time version of the Ramsey economy, introducing the modified one-period borrowing constraint. In section 4, we define the Ramsey equilibrium and the stationary Ramsey equilibrium. Section 5 contains our main results on the convergence of the capital input path in every Ramsey equilibria with the one period borrowing constraint. We conclude in section 6 . 


\section{Preliminaries}

In this section we describe the characteristics of the production technology and households. This part of the model is standard in the literature on the Ramsey economy.

\subsection{Production Technology}

Production takes place using a single capital good. The production technology turns labor and capital goods into a composite good that can be either consumed or invested as next period's capital goods input. The amount of labor is fixed in this economy. There is one unit of labor services in the aggregate in this economy and all labor services are assumed to be identical. The technology is summarized by a production function, denoted by $f$. Let $y=f(k)$ denote the composite good $y$ produced from one unit labor (whose value is suppressed in the notation), together with a nonnegative capital input $k$. Capital is assumed to depreciate completely within one period. Hence, the model is formally one with circulating capital that is consumed within one production period. The output $y$ is available for consumption or capital accumulation. The formal properties of $f$ are:

Assumption 1. The production function $f: \mathbb{R}_{+} \rightarrow \mathbb{R}_{+}$is continuous, increasing and concave on $\mathbb{R}_{+}$and satisfies $f(0)=0$. Also, $f$ is $\mathscr{C}^{2}$ on $\mathbb{R}_{++}$, with

$$
f^{\prime}(\cdot)>0 \text {; and } f^{\prime \prime}(\cdot)<0 \text {; on } \mathbb{R}_{++}, \lim _{k \rightarrow 0} f^{\prime}(k)=\infty, \lim _{k \rightarrow \infty} f^{\prime}(k)=0 .
$$

This assumption implies there is a maximum sustainable capital stock, denoted by $\bar{K}$, satisfying $\bar{K}=f(\bar{K})>0$.

\subsection{Households}

There are $J \geq 1$ households indexed by $j=1, \cdots, J$. Let $c_{t}^{j}$ and $s_{t}^{j}$ denote the consumption and savings of household $j$ at time $t$ respectively. Agents preferences assume time additively separable utility functions with fixed discount factors. Household $j$ has felicity function $u_{j} ; c_{t}^{j}$ is the argument of $u_{j}$. Household $j$ discounts future utilities by the factor $\beta_{j}$ with 
$0<\beta_{j}<1$. Hence, the household's lifetime utility function is specified by $\sum_{t=0}^{\infty} \beta_{j}^{t} u_{j}\left(c_{t}^{j}\right)$. The felicity functions satisfy the following properties.

Assumption 2. For each $j, u_{j}: \mathbb{R}_{+} \rightarrow \mathbb{R}$ is continuous, increasing and concave on $\mathbb{R}_{+}$and $\mathscr{C}^{2}$ on $\mathbb{R}_{++}$with $u_{j}^{\prime}(\cdot)>0, u_{j}^{\prime \prime}(\cdot)<0$ on $\mathbb{R}_{++}$and $\lim _{c \rightarrow 0} u_{j}^{\prime}(c)=\infty$.

We focus on the case where the first household's discount factor is larger than all the other households' discount factors. Assumption 3 orders households from the most patient to the least patient ${ }^{2}$.

Assumption 3. $1>\beta_{1}>\beta_{2} \geq \cdots \geq \beta_{J}>0$.

Assumptions 1-3 are maintained for the remainder of this paper. If $J=1$, then the Ramsey equilibrium model coincides with the standard optimal growth problem. We assume $J \geq 2$ in the sequel.

\section{The Ramsey Economy}

In this section, we describe the nature of the borrowing constraint and the optimizing behavior of households and firms.

\subsection{Borrowing Constraint}

A general complete market competitive one-sector model treats budget constraints as restricting the present value of an agent's consumption to be smaller than or equal to the agent's initial wealth defined as the capitalized wage income plus that person's initial savings. This allows us to interpret the choice of a consumption stream as if the agent is allowed to borrow and lend at market determined present value prices subject to repaying all loans. Markets are complete - any intertemporal trade satisfying the present value budget constraint is admissible at the individual level.

The Ramsey equilibrium model changes the budget constraint from a single one (reckoned as a present value) to a sequence, one for each period.

\footnotetext{
${ }^{2}$ It is not difficult to generalize our results to the case where the subset of the most patient households consists of more then one household.
} 
Agents are forbidden to borrow against their future labor income, so they cannot capitalize the future wage stream into a present value. Markets are incomplete; individuals are debt constrained. The operation of a borrowing constraint in the individual household problems also breaks the possibility of an equilibrium allocation arising as an economy's Pareto optimal allocation.

In this paper, we introduce limited borrowing in the following manner. At each time $t$, based on the initial savings at time $t-1$, which are not assumed to be non-negative, and the wage income accrued from working at time $t$, the household's total income is realized. Given their total incomes, households make the consumption - savings choice. Again, when making this choice, they are not prohibited from borrowing (equivalently having negative savings). At the beginning of the production period they are allowed to borrow against the wage they will earn at the end of the period. This borrowing can take place at the market rental rate. Markets continue to be incomplete; however households are relatively less debt constrained. The continued operation of a partial borrowing constraint in the households' problems breaks the possibility of an equilibrium allocation arising as an economy's Pareto optimal allocation.

\subsection{The Households' Problems}

Let $\left\{1+r_{t}, w_{t}: t=0,1, \cdots\right\}$ be a sequence of one period rental returns and wage rates, respectively. The sequences $\left\{1+r_{t}, w_{t}\right\}$ are always taken to be positive. Households are competitive agents and perfectly anticipate the profile of factor returns $\left\{1+r_{t}, w_{t}\right\}$.

At time $t$, each household can borrow against the wage earned for the labor at time $t+1$. Thus a household could have negative savings at any time $t$ which is bounded below by the prevailing wage:

$$
-\left(1+r_{t+1}\right) s_{t}^{j} \leq \frac{w_{t+1}}{J}, \quad \text { or } \quad s_{t}^{j}+\frac{w_{t+1}}{\left(1+r_{t+1}\right) J} \geq 0 .
$$


At time $t=0$, we are given $s_{-1}^{j}$ such that

$$
s_{-1}^{j}+\frac{w_{0}}{\left(1+r_{0}\right) J} \geq 0 ; \quad \text { and } \quad \sum_{j=1}^{J} s_{-1}^{j}=k_{0}>0 .
$$

Given $\left\{1+r_{t}, w_{t}\right\}$, household $j$ solves

$$
P(j): \quad \sup \sum_{t=0}^{\infty} \beta_{j}^{t} u_{j}\left(c_{t}^{j}\right),
$$

by choice of a nonnegative consumption sequence $\left\{c_{t}^{j}\right\}$, and a savings sequence $\left\{s_{t}^{j}\right\}$ such that

$$
c_{t}^{j}+s_{t}^{j}=\left(1+r_{t}\right) s_{t-1}^{j}+\frac{w_{t}}{J}, s_{t}^{j}+\frac{w_{t+1}}{\left(1+r_{t+1}\right) J} \geq 0 ; \quad t=0,1,2, \cdots .
$$

The first-order conditions of optimality (Ramsey-Euler inequalities) for the problem $P(j)$ are

$$
\frac{u_{j}^{\prime}\left(c_{t}^{j}\right)}{u_{j}^{\prime}\left(c_{t-1}^{j}\right)} \geq \frac{1}{\beta_{j}\left(1+r_{t}\right)}\left(=\text { if } s_{t-1}^{j}+\frac{w_{t}}{\left(1+r_{t}\right) J}>0\right), \quad t=1,2, \cdots
$$

\subsection{The Production Sector's Objective}

All the intertemporal decisions are taken in the household sector. Producers are supposed to take the rental rate as given and solve the following myopic profit maximization problem $P(F)$ at each $t$ :

$$
P(F): \quad \sup \left[f(K)-\left(1+r_{t}\right) K\right],
$$

by choice of $K \geq 0$. The residual profit is treated as the wage bill. It is shared equally by the identical households as wages - production is worker owned.

If $0<1+r_{t}<\infty$, then Assumption 1 implies there is a unique positive stock $K_{t}$ which solves $P(F)$ at each $t$; clearly

$$
f^{\prime}\left(K_{t}\right)=1+r_{t}
$$


furthermore, the corresponding $w_{t}$ is positive and is defined by

$$
w_{t}=f\left(K_{t}\right)-\left(1+r_{t}\right) K_{t} .
$$

\section{The Ramsey Equilibrium Concept}

A collection $\mathscr{E}=\left(f, k_{0},\left\{u_{j}, \beta_{j}, s_{-1}^{j}\right\}, j=1,2, \cdots, J\right)$ satisfying Assumptions 1 - 3 such that

$$
\sum_{j=1}^{J} s_{-1}^{j}=k_{0}>0, s_{-1}^{j}+\frac{w_{0}}{\left(1+r_{0}\right) J} \geq 0 \text { for each } j \text { and } k_{0} \leq \bar{K}
$$

is said to be an economy. The economy always has a positive aggregate capital stock and at least one agent always have positive savings at time zero.

The equilibrium concept is perfect foresight. Households perfectly anticipate the sequences of rental and wage rates. They solve their optimization problems for their planned consumption demand and saving sequences. The production sector calculates the capital demand at each time and the corresponding total output supply. Rents are paid to the households for capital supplied and the residual profits are paid out as the total wage bill.

An equilibrium occurs when the households' savings supply equals the production sector's capital demand at every point of time. A form of Walras' law implies that the total consumption demand plus supply of savings for the next period equals current output. Thus, in equilibrium, every agent maximizes its objective function and planned supplies equal planned demands in every market.

Definition 1. Sequences $\left\{1+r_{t}, w_{t}, K_{t},\left(c_{t}^{j}, s_{t}^{j}\right), j=1, \cdots, J ; t=0,1, \cdots\right\}$ constitute a Ramsey equilibrium for a given economy $\mathscr{E}$ provided:

(E1) For each $j,\left(c_{t}^{j}, s_{t}^{j}\right)$ solves $P(j)$ given $\left\{1+r_{t}, w_{t} ; t=0,1, \cdots\right\}$.

(E2) For each $t, K_{t}$ solves $P(F)$ given $1+r_{t}$.

(E3) $w_{t}=f\left(K_{t}\right)-\left(1+r_{t}\right) K_{t}$ for $t=0,1,2, \cdots$. 
(E4) $\sum_{j=1}^{J} s_{t-1}^{j}=K_{t}$ for $t=1,2, \cdots$, and $0<k_{0}=K_{0} \leq \bar{K}$.

The output market balance follows by combining (E1) - (E4):

$$
\sum_{j=1}^{J} c_{t}^{j}+\sum_{j=1}^{J} s_{t}^{j}=f\left(K_{t}\right), t=0,1,2, \cdots .
$$

Note that the equilibrium consumption, savings and capital sequences are bounded from above by the maximum sustainable stock $\bar{K}$. The assumed conditions for households and the producer imply that in an equilibrium, $c_{t}^{j}>0, j=1, \cdots, J$, and $K_{t}>0$ for each $t$, given that $k_{0}$ is positive. Each agent's total income, $\left(1+r_{t}\right) s_{t-1}^{j}+\frac{w_{t}}{J}$, is non-negative at each time, but may be equal to zero. At least one household's savings are positive at each time along an equilibrium profile. By using the arguments developed in Becker et al. (1991), it is possible to show that an equilibrium exists in this model. We next define the stationary equilibrium, which is generally the first one investigated in the literature,

Definition 2 (Stationary Ramsey Equilibrium). A tuple $\{1+$ $\left.r^{*}, w^{*}, K^{*},\left(c^{j *}, s^{j *}\right), j=1, \cdots, J\right\}$ is called a stationary Ramsey equilibrium if the sequences $\left\{1+r_{t}, w_{t}, K_{t},\left(c_{t}^{j}, s_{t}^{j}\right), j=1, \cdots, J ; t=0,1, \cdots\right\}$ given by

$$
1+r_{t}=1+r^{\star}, w_{t}=w^{\star}, K_{t}=K^{\star}, c_{t}^{j}=c^{j \star}, s_{t}^{j}=s^{j \star} ; t=0,1, \cdots
$$

represent a Ramsey equilibrium.

The following proposition can be proved in the same way as the main result in Becker (1980).

Proposition 1. There is a unique stationary Ramsey equilibrium

$$
\left\{1+r^{*}, w^{*}, K^{*},\left(c^{j *}, s^{j *}\right), j=1, \cdots, J\right\},
$$

which is determined as follows:

$$
1+r^{*}=\frac{1}{\beta_{1}}, f^{\prime}\left(K^{*}\right)=1+r^{*}, w^{*}=f\left(K^{*}\right)-K^{*} f^{\prime}\left(K^{*}\right)
$$




$$
s^{1^{*}}=K^{*}+\left(\frac{J-1}{J}\right) \cdot \frac{w^{*}}{\left(1+r^{*}\right)}, c^{1^{*}}=\frac{w^{*}}{J}+r^{*} s^{1^{*}}
$$

and

$$
c^{j^{*}}=-s^{j^{*}}=\frac{w^{*}}{\left(1+r^{*}\right) J}, j=2, \cdots, J .
$$

Observe that with Assumption 1 imposed on the production function, $K^{*}$ is uniquely determined. This proposition maintains that in the stationary Ramsey equilibrium all households except the most patient one are indebted and all their wage incomes are spent for the payment of their debts. The impatient households never own capital and in every period they consume by borrowing against the end of the period wage income. Therefore, their consumption is positive as the borrowing limit is positive in every period (wage income discounted by the rental rate). As for the most patient household, it owns all capital and all debts of the other households. It is clear that the stationary-equilibrium capital stock and output in our economy are the same as in the no-borrowing economy. However, the output is distributed among the agents in a somewhat different way: the consumption of the most patient household is higher and the consumption of every other household is lower than in the no-borrowing economy.

\section{Convergence and the Turnpike Property}

Now we are ready to prove our main result.

Theorem 1. Let $\left\{1+r_{t}, w_{t}, K_{t},\left(c_{t}^{j}, s_{t}^{j}\right), j=1, \cdots, J ; t=0,1, \cdots\right\}$ be a Ramsey equilibrium. Then,

(i) $\left\{K_{t}\right\}$ converges to $K^{*}$,

(ii) there is $S \in \mathbb{N}$ such that for every $j \in\{2, \cdots, J\}, s_{t}^{j}+\frac{w_{t+1}}{\left(1+r_{t+1}\right) J}=0$ for all $t \geq S$.

This theorem maintains the convergence property of the capital input path and the turnpike property of the capital ownership pattern among 
the patient and other households ${ }^{3}$. Observe that these two properties are established without imposing any additional restriction on the production function (like capital income monotonicity or maximal income monotonicity). Following Theorem 4 in Becker and Mitra (2012), it is easy to show that the aggregate consumption sequence is efficient

Our proof of the theorem is essentially the same as the proof of the main result in Becker and Foias (1987). First, we state the following lemma.

Lemma 1. Let $\left\{1+r_{t}, w_{t}, K_{t},\left(c_{t}^{j}, s_{t}^{j}\right), j=1, \cdots, J\right\}$ be a Ramsey equilibrium, such that $\left\{K_{t}\right\}$ is convergent. Then, there is $T \in \mathbb{N}$ such that for every $j \in\{2, \cdots, J\}$, $s_{t}^{j}+\frac{w_{t+1}}{\left(1+r_{t+1}\right) J}=0$ for all $t \geq T$.

Proof. It is similar to the proof of Proposition 4 in Becker and Foias (1987).

Now we look at the implications of non-convergence of capital stocks along a Ramsey Equilibrium path. Specifically, we show that if the capital stock exceeds $K^{*}$ for a subsequence of periods, then among these periods there must be one where the capital stock attains a "local maximum". After that we show that the one period borrowing constraint rules out precisely this kind of "local maximum".

Lemma 2. Let $\left\{1+r_{t}, w_{t}, K_{t},\left(c_{t}^{j}, s_{t}^{j}\right), j=1, \cdots, J ; t=0,1, \cdots\right\}$ be a Ramsey equilibrium, such that $\left\{K_{t}\right\}$ is not convergent. Suppose there is a subsequence of periods for which $\beta_{1} f^{\prime}\left(K_{t}\right)<1$. Then there is $N \in \mathbb{N}$ such that:

(i) $K_{N-1} \leq K_{N} ; \quad K_{N+1}<K_{N}$ ，

(ii) $\beta_{1} f^{\prime}\left(K_{N}\right)<1$.

Proof. Since $\left\{K_{t-1}\right\}$ is not convergent, we have:

$$
a \equiv \limsup _{t \rightarrow \infty} K_{t}>\liminf _{t \rightarrow \infty} K_{t} \equiv b .
$$

\footnotetext{
${ }^{3}$ To be more precise, this theorem maintains a little more than the turnpike property: from some time onwards, all households except the most patient one get indebted and spend all their wage incomes for the payment of their debts whereas the most patient household becomes the owner of all capital and all debts of the other agents.
} 
Denote $(a-b)$ by $\theta$. Since $\liminf _{t \rightarrow \infty} K_{t}=b$, we can pick:

$$
T_{1}=\min \left\{t \in \mathbb{N}: K_{t}<b+\frac{\theta}{3}\right\} .
$$

Since there is a subsequence of periods for which $\beta_{1} f^{\prime}\left(K_{t}\right)<1$, we have $K_{t}>K^{*}$ for that subsequence of periods. So, we can pick:

$$
T_{2}=\min \left\{t \in \mathbb{N}: t>T_{1} \text { such that } K_{t}>K^{*}\right\} .
$$

Since $a=\limsup _{t \rightarrow \infty} K_{t}$, we can pick:

$$
T_{3}=\min \left\{t \in \mathbb{N}: t>T_{2} \text { such that } K_{t}>a-\frac{\theta}{3}\right\} .
$$

And, since $\liminf _{t \rightarrow \infty} K_{t}=b$, we can pick:

$$
T_{4}=\min \left\{t \in \mathbb{N}: t>T_{3} \text { such that } K_{t}<b+\frac{\theta}{3}\right\} .
$$

Define

$$
m=\max \left\{K_{t}: T_{1} \leq t \leq T_{4}\right\}
$$

Then

$$
\begin{aligned}
& \text { (i) } m>K^{*} \\
& \text { (ii) } m>a-\frac{\theta}{3}>b+\frac{\theta}{3} .
\end{aligned}
$$

Now define

$$
N=\max \left\{T_{1} \leq t \leq T_{4}: K_{t}=m\right\} .
$$

Then, using (3)(ii), we have $N<T_{4}$ and $N>T_{1}$. Further, by definition of $m$, we have $K_{N-1} \leq K_{N}$ and by definition of $N$, we have $K_{N+1}<K_{N}$. Also, by (3)(i), $K_{N}>K^{*}$ and so $\beta_{1} f^{\prime}\left(K_{N}\right)<1$. This completes the proof of the lemma.

Lemma 3. Let $\left\{1+r_{t}, w_{t}, K_{t},\left(c_{t}^{j}, s_{t}^{j}\right), j=1, \cdots, J ; t=0,1, \cdots\right\}$ be a Ramsey equilibrium. If there is $N \in \mathbb{N}$ such that:

$$
K_{N-1} \leq K_{N} ; \quad K_{N+1}<K_{N},
$$

then:

$$
\beta_{1} f^{\prime}\left(K_{N}\right)>1 .
$$


Proof. Suppose the condition $K_{N-1} \leq K_{N}$ and $K_{N+1}<K_{N}$ is satisfied for some $N \in \mathbb{N}$, but the condition $\beta_{1} f^{\prime}\left(K_{N}\right)>1$ is violated. Then

$$
\beta_{1} f^{\prime}\left(K_{N}\right)=\beta_{1}\left(1+r_{N}\right) \leq 1
$$

Let $\Gamma=\left\{j \in\{1, \cdots, J\}: s_{N-1}^{j}+\frac{w_{N}}{\left(1+r_{N}\right) J}>0\right\}$. Denote the cardinality of $\Gamma$ by $\gamma$. Let us first show that

$$
\left(1+r_{N}\right) \sum_{j \in \Gamma}\left(s_{N-1}^{j}+\frac{w_{N}}{\left(1+r_{N}\right) J}\right) \geq\left(1+r_{N-1}\right) \sum_{j \in \Gamma}\left(s_{N-2}^{j}+\frac{w_{N-1}}{\left(1+r_{N-1}\right) J}\right) .
$$

Since $f\left(K_{N}\right) \geq f\left(K_{N-1}\right)$, we have

$$
\begin{aligned}
\left(1+r_{N}\right) \sum_{j \in \Gamma}\left(s_{N-1}^{j}+\frac{w_{N}}{\left(1+r_{N}\right) J}\right) & =\left(1+r_{N}\right) \sum_{j=1}^{J}\left(s_{N-1}^{j}+\frac{w_{N}}{\left(1+r_{N}\right) J}\right) \\
& =\left(1+r_{N}\right) \sum_{j=1}^{J} s_{N-1}^{j}+w_{N}=\left(1+r_{N}\right) K_{N}+w_{N} \\
& =f\left(K_{N}\right) \geq f\left(K_{N-1}\right) \\
& =\left(1+r_{N-1}\right) K_{N-1}+w_{N-1}=\left(1+r_{N-1}\right) \sum_{j=1}^{J} s_{N-2}^{j}+w_{N-1} \\
& =\left(1+r_{N-1}\right) \sum_{j=1}^{J}\left(s_{N-2}^{j}+\frac{w_{N-1}}{\left(1+r_{N-1}\right) J}\right) \\
& \geq\left(1+r_{N-1}\right) \sum_{j \in \Gamma}\left(s_{N-2}^{j}+\frac{w_{N-1}}{\left(1+r_{N-1}\right) J}\right),
\end{aligned}
$$

which proves (5). Now note that for each $j \in \Gamma$, by (4) and the first-order conditions,

$$
\frac{u_{j}^{\prime}\left(c_{N}^{j}\right)}{u_{j}^{\prime}\left(c_{N-1}^{j}\right)}=\frac{1}{\beta_{j}\left(1+r_{N}\right)}=\frac{1}{\beta_{j} f^{\prime}\left(K_{N}\right)} \geq 1
$$


Therefore, for each $j \in \Gamma$, we get $c_{N}^{j} \leq c_{N-1}^{j}$, and hence, attracting (5),

$$
\left(1+r_{N}\right) \sum_{j \in \Gamma}\left(s_{N-1}^{j}+\frac{w_{N}}{\left(1+r_{N}\right) J}-c_{N}^{j}\right) \geq\left(1+r_{N-1}\right) \sum_{j \in \Gamma}\left(s_{N-2}^{j}+\frac{w_{N-1}}{\left(1+r_{N-1}\right) J}-c_{N-1}^{j}\right) .
$$

We have

$$
\begin{aligned}
K_{N}+\frac{w_{N}}{1+r_{N}} & =\sum_{j=1}^{J}\left(s_{N-1}^{j}+\frac{w_{N}}{\left(1+r_{N}\right) J}\right) \\
& =\sum_{j \in \Gamma}\left(s_{N-1}^{j}+\frac{w_{N}}{\left(1+r_{N}\right) J}\right) \\
& =\sum_{j \in \Gamma}\left[\left(1+r_{N-1}\right)\left(s_{N-2}^{j}+\frac{w_{N-1}}{\left(1+r_{N-1}\right) J}\right)-c_{N-1}^{j}+\frac{w_{N}}{\left(1+r_{N}\right) J}\right]
\end{aligned}
$$

and hence

$$
K_{N}=\sum_{j \in \Gamma}\left[\left(1+r_{N-1}\right)\left(s_{N-2}^{j}+\frac{w_{N-1}}{\left(1+r_{N-1}\right) J}\right)-c_{N-1}^{j}\right]-\left(\frac{J-\gamma}{J}\right) \frac{w_{N}}{\left(1+r_{N}\right)}
$$

Also we have

$$
\begin{aligned}
K_{N+1}+\frac{w_{N+1}}{1+r_{N+1}} & =\sum_{j=1}^{J}\left(s_{N}^{j}+\frac{w_{N+1}}{\left(1+r_{N+1}\right) J}\right) \\
& \geq \sum_{j \in \Gamma}\left(s_{N}^{j}+\frac{w_{N+1}}{\left(1+r_{N+1}\right) J}\right) \\
& =\sum_{j \in \Gamma}\left[\left(1+r_{N}\right)\left(s_{N-1}^{j}+\frac{w_{N}}{\left(1+r_{N}\right) J}\right)-c_{N}^{j}+\frac{w_{N+1}}{\left(1+r_{N+1}\right) J}\right] .
\end{aligned}
$$

and hence

$$
K_{N+1} \geq \sum_{j \in \Gamma}\left[\left(1+r_{N}\right)\left(s_{N-1}^{j}+\frac{w_{N}}{\left(1+r_{N}\right) J}\right)-c_{N}^{j}\right]-\left(\frac{J-\gamma}{J}\right) \frac{w_{N+1}}{\left(1+r_{N+1}\right)} .
$$

At the same time it follows from $K_{N+1}<K_{N}$ that $\frac{w_{N+1}}{1+r_{N+1}}<\frac{w_{N}}{1+r_{N}}$. Taking account of (6), we get $K_{N+1}>K_{N}$, which contradicts our assumptions. 
Combining the last two lemmas, it follows that, under one period borrowing constraint, either (i) a Ramsey Equilibrium path is convergent, or (ii) its capital stock sequence is eventually always less than or equal to $K^{*}$. However, the latter scenario itself also implies convergence, as can be verified easily from the Euler inequalities.

Proof of Theorem 1. We establish (i) as follows. Suppose that, contrary to (i), $\left\{K_{t}\right\}$ is not convergent. If $\beta_{1} f^{\prime}\left(K_{t+1}\right)<1$ for a subsequence of periods, then by Lemma 2, there is $N \in \mathbb{N}$ such that:

$$
\begin{aligned}
\text { (i) } & K_{N} \leq K_{N+1} ; \quad K_{N+2}<K_{N+1}, \\
\text { (ii) } & \beta_{1} f^{\prime}\left(K_{N+1}\right)<1 .
\end{aligned}
$$

However, (7) (i) implies by Lemma 3 that $\beta_{1} f^{\prime}\left(K_{N+1}\right)>1$, which contradicts (7) (ii). Thus, there is $T \in \mathbb{N}$ such that

$$
\beta_{1} f^{\prime}\left(K_{T}\right) \geq 1 \text { for all } t \geq T \text {. }
$$

Using the Ramsey-Euler inequality for household 1, we get

$$
\frac{u_{1}^{\prime}\left(c_{t+1}^{1}\right)}{u_{1}^{\prime}\left(c_{t}^{1}\right)} \leq \frac{1}{\beta_{1} f^{\prime}\left(K_{t+1}\right)} \text { for all } t \geq T .
$$

Thus, we must have

$$
c_{t+1}^{1} \geq c_{t}^{1} \text { for all } t \geq T .
$$

This implies that $\left\{c_{t}^{1}\right\}$ must converge to some $c^{\prime}>0$, and using this in (9), we have

$$
\limsup _{t \rightarrow \infty} \beta_{1} f^{\prime}\left(K_{t}\right) \leq 1 .
$$

On the other hand, by (8), we have

$$
\liminf _{t \rightarrow \infty} \beta_{1} f^{\prime}\left(K_{t}\right) \geq 1
$$

Thus,

$$
\liminf _{t \rightarrow \infty} \beta_{1} f^{\prime}\left(K_{t}\right)=1=\limsup _{t \rightarrow \infty} \beta_{1} f^{\prime}\left(K_{t}\right) .
$$

But this means that $\left\{K_{t}\right\}$ is convergent, a contradiction. This establishes (i).

Using (i), we see that (ii) follows from Lemma 1. This establishes the Theorem. 


\section{Conclusion}

It is well known that in a standard discrete time Ramsey economy, the extreme form of the borrowing constraint on households requires very strict conditions on the production function in order to obtain desirable asymptotic properties of capital stock sequences. In contrast to this, by allowing limited borrowing (even for one period) by households, we achieve a convergent and efficient allocation of resources irrespective of the assumptions made about technology.

It should be noted that the form of the borrowing constraint plays an important role in our argument. We assume that at the beginning of each period, households are allowed to borrow against their end of the period wage income. However, if we replace the no-borrowing constraint by the constraint $s_{t}^{j} \geq \underline{s}$ (where $\underline{s}<0$ and is given exogenously), this will not guarantee convergence of the sequence of the capital stock irrespective of technology.

Our results might shed some light on the difference among the results in discrete and continuous time Ramsey models, because the continuous-time Ramsey model with the no-debt constraint could be considered as a limiting case of the discrete-time Ramsey model with the one period borrowing constraint. This aspect could be a topic of future research. 


\section{References}

R. A. Becker. On the Long-Run Steady State in a Simple Dynamic Model of Equilibrium with Heterogeneous Households. Quarterly Journal of Economics, 95(2):375-382, 1980.

R. A. Becker. Equilibrium Dynamics with Many Agents. In Rose-Anne Dana, C. Le Van, T. Mitra, and K. Nishimura, editors, Handbook of Optimal Growth 1. Springer-Verlag, 2006.

R. A. Becker and C. Foias. A Characterization of Ramsey Equilibrium. Journal of Economic Theory, 41:173-184, 1987.

R. A. Becker and T. Mitra. Efficient Ramsey Equilibria. Macroeconomic Dynamics, 16(Supplement S1):18-32, 2012.

R. A. Becker, J. H. Boyd, and C. Foias. The Existence of Ramsey Equilibrium. Econometrica, 59(2):441-460, 1991.

R. A. Becker, R. S. Dubey, and T. Mitra. On Ramsey Equilibrium: Capital Ownership Pattern and Inefficiency. Economic Theory, forthcoming, 2013.

T. F. Bewley. An integration of equilibrium theory and turnpike theory. Journal of Mathematical Economics, 10:233-267, 1982.

K. Borissov. On equilibrium dynamics with many agents and wages paid ex ante. Department of Economics, European University at St. Petersburg, Working Paper(Ec-5/11), 2011.

E. Malinvaud. Capital Accumulation and Efficient Allocation of Resources. Econometrica, 21(2):233-268, 1953.

T. Mitra and G. Sorger. On Ramsey's conjecture. Journal of Economic Theory, forthcoming, 2013.

F. P. Ramsey. A mathematical theory of saving. Economic Journal, 38:543$559,1928$. 